\title{
Karyotyping the Arabian Camel (Camelus dromedarius), Using C-Banding Technique
}

\author{
Mohammed A. Samman ${ }^{1}$, Abdulaziz A. Al-Saleh ${ }^{2}$ and Kart Sheth ${ }^{1}$ \\ ${ }^{1}$ Research Center, King Faisal Specialist Hospital, Riyadh. \\ ${ }^{2}$ Department of Zoology, College of Science, King Saud University, \\ Riyadh, P. O. Box 2455, Saudi Arabia
}

Accepted March 5, 1992

The development of various staining techniques has been essential for the precise identification of chromosome morphology. Since the chromosomes of each species are unique, the C-banding staining has contributed immensely to the understanding of chromosome structure in eukaryotes. This technique was originally discovered by Pardue and Gall (1970) and was later modified by Arrighi and Hsu (1971). These bands are so termed because they involve the selective staining of constitutive heterochromatin in the region of the centromere. Hence, the bands are called $\mathrm{C}$-bands in relation to the constitutive heterochromatin. It is now known that C-band chromatin contains a special type of DNA composed of very high repetitions of short sequences (Pardue and Galls 1970). Although constitutive heterochromatin is visible in untreated prophase chromosomes, it is better observed in condenced metaphase chromosomes by C-banding (Arrighi and Hsu 1970, Craig-Holmes and Shaw 1971, Sumner 1972).

The technique was used to study various mammalian families like the Muridae (Prescott et al. 1973, Bostock and Christie 1974, Schnedl and Czaker 1974, Dev et al. 1975), Bovidae (Evans et al. 1973, Bruere et al. 1974, Buckland and Evans 1978, Di Berardino and Iannuzzi 1981, Switonski 1987, Berland et al. 1988) and Cervidae (Jorge and Benirschke 1977, Van Tuinen et al. 1983, Goldoni et al. 1984, Mayr et al. 1987). This technique is yet to be used in the Camelidae apart from a single report by Bunch et al. (1985) describing G- and C- banding pattern homologies as well as chromosomes with NORs for Bactrian camels, Ilamas, and guanacos. Hence, in the present study the C-banding technique is used for the identification of $C$. dromedarius chromosomes in vitro.

\section{Materials and methods}

Venous blood was obtained from 10 male and 10 female camels from the King Saud University Animal Farm, under the sterile hood and using asceptic techniques, $10 \mathrm{ml}$ of sterile complete growth medium (RPMI-1640) were put into a $25 \mathrm{~cm}^{2}$ sterile culture flask, then 0.2 $\mathrm{ml}$ of sterile phytohemagglutinin (PHA) was added to the flask. An aliquot of $0.5 \mathrm{ml}$ of blood was drawn from well suspended blood sample using a $1 \mathrm{ml}$ disposable syringe fitted with $21 \mathrm{G}$ needle and added into the flask. The flask was inverted several times before incubating at $37^{\circ} \mathrm{C}$ in an incubator supplied with continous flow of $5 \% \mathrm{CO}_{2}$ and $80 \%$ humidity. After $72 \mathrm{hr}$ of incubation and $1 \mathrm{hr}$ before harvesting the cell culture, 2 drops of colcemid (10 $\mu \mathrm{g} / \mathrm{ml}$ ) were added to the culture flask in order to synchroinize the dividing cells at the metaphase stage. The cultured cells were then harvested by vigorous shaking the flask before transfering the cell suspension into centrifuge tube. The cell suspension was then centrifuged at $100 \mathrm{~g}$ for $10 \mathrm{~min}$. The supernatant removed under vacuum and the pellet of cells were resuspended in $5 \mathrm{ml}$ of $0.075 \mathrm{M} \mathrm{KCl}$ and incubated in a water bath at $37^{\circ} \mathrm{C}$ for $15 \mathrm{~min}$ as a hypotonic treatment. The cell suspension was then centrifuged and the cells were

2 Reprint requist from: Prof A. A. Al-Saleh 
fixed in 3:1 absolute methanol-glacial acetic acid for a minimum of $30 \mathrm{~min}$. The fixation procedure was repeated three times before spreading the cells on the slides.

The original method described by Arrighi and Hsu (1971) involves primary treatment with an alkali, sodium hydroxide $(\mathrm{NaOH})$ to denature the chromosomal DNA and subsequent incubation in a salt solution. In modified method described by Sumner (1972), a milder alkali, barium hydroxide $\left(\mathrm{Ba}(\mathrm{OH})_{2}\right)$, is used instead of $\mathrm{NaOH}$. Both of these methods produce a similar characteristic pattern of $\mathrm{C}$-bands. The later method may provide an advantage, because they facilitate better control of the denaturation of the chromosomes except for the centromere (constitutive heterochromatin) bands. The chromosomes preparations were obtained from peripheral blood cultures as described as above were allowed to age for 1-2 weeks before treating them with freshly prepared and filtered $2.5 \%$ barium hydroxide solution for $8 \mathrm{~min}$ at room temperature. After thorough rinsing in several changes of distilled water to remove as much salt deposites as possible, the slides were incubated for $2 \mathrm{hr}$ at $60^{\circ} \mathrm{C}$ in

\section{|| || | || || || || $\|$ \\ || || || || || || || || \\ 1101111 iा 11 : 18 :

 \\ 915089000000

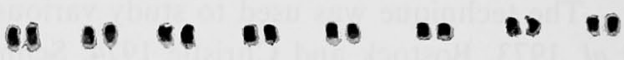

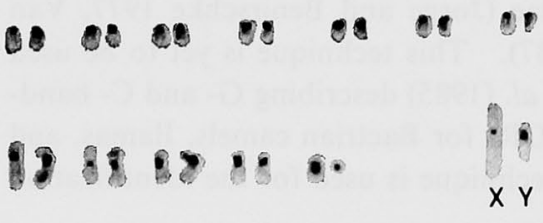 \\ Fig. 1. C-banded karyotype of male C. dromedarius. $\times 5000$

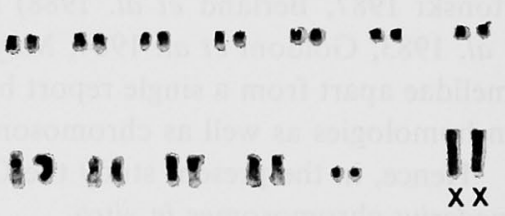 \\ Fig. 2. C-banded karyotype of female C. dromedarius. $\times 5000$}

$2 \times$ SSC ( $0.3 \mathrm{M}$ sodium chloride containg $0.03 \mathrm{M}$ tri-sodium citrate), rinsed briefly with distilled water and stained with 5\% Giemsa stain for 5-15 min. Finally the slides were again rinsed briefly in distilled water, blotted, allowed to dry throughly, soaked in xylene and mounted in DPX. They were examined for metaphase stages under Nikon microscope with $25 \times$ planchromatic objective and $10 \times$ eyepieces. Photomicrographs of selective metaphase chromosomes were taken under bright field illumination, using $100 \times$ oil immersion objective and $10 \times$ eyepiece. The arm ratios were calculated according to the proposal of Levan et al. (1964) using an electronic caliper, Fowler Ultra-Cell II (Fowler Co.).

\section{Results}

The diploid chromosome number (2n) for the camel, $C$. dromedarius are 74 and the findings of C-band technique are present in Figs. 1 and 2. The chromosomes were divided according to the position of the centromere, into three types: Type 1 comprises acrocentric autosomes number 1-31, type 2 metacentric autosomes number 32, 33, 34 and the $\mathrm{X}$ and $\mathrm{Y}$ chromosomes 
and type 3 represents one pair of submetacentric autosomes number 35 .

All the acrocentric autosomes have a paracentric C-band which varies greatly in width. The amount of centromeric heterochromatin in bi-armed chromosomes was generally reduced relative to acrocentric autosomes. An interstitial C-band was not found in any of the chromosomes of the dromedary.

Table. 1. The relative mean lengths and arm ratio measurements in $\mathrm{mm}$ of the 74 mitotic chromosomes of Arabian camel $C$. dromedarius

\begin{tabular}{|c|c|c|c|c|c|}
\hline $\begin{array}{c}\text { Type of } \\
\text { Chromosome }\end{array}$ & $\begin{array}{l}\text { Total } \\
\text { Length }\end{array}$ & $\begin{array}{l}\text { Length of } \\
\text { long arm } \\
\text { (q) }\end{array}$ & $\begin{array}{l}\text { Length of } \\
\text { short arm } \\
\text { (p) }\end{array}$ & $\begin{array}{l}\text { Arm ratio } \\
\mathbf{q} / \mathbf{p}\end{array}$ & $\begin{array}{l}\text { Type of } \\
\text { Centromere }\end{array}$ \\
\hline 1 & 13.79 & 11.54 & 2.25 & 5.13 & A \\
\hline 2 & 12.21 & 10.52 & 1.69 & 6.22 & A \\
\hline 3 & 11.78 & 10.03 & 1.75 & 5.73 & A \\
\hline 4 & 10.87 & 9.09 & 1.78 & 5.11 & A \\
\hline 5 & 10.19 & 8.54 & 1.65 & 5.18 & A \\
\hline 6 & 9.49 & 7.83 & 1.66 & 4.72 & A \\
\hline 7 & 8.90 & 7.54 & 1.36 & 5.54 & A \\
\hline 8 & 7.88 & 6.64 & 1.24 & 5.35 & A \\
\hline 9 & 7.67 & 6.55 & 1.12 & 5.85 & A \\
\hline 10 & 7.35 & 6.09 & 1.26 & 4.83 & A \\
\hline 11 & 7.20 & 5.66 & 1.54 & 3.67 & A \\
\hline 12 & 6.96 & 5.88 & 1.08 & 5.44 & A \\
\hline 13 & 6.38 & 5.14 & 1.24 & 4.14 & A \\
\hline 14 & 6.02 & 4.76 & 1.26 & 3.77 & A \\
\hline 15 & 5.11 & 4.10 & 1.01 & 4.10 & $\mathbf{A}$ \\
\hline 16 & 4.35 & 3.38 & 0.97 & 3.48 & A \\
\hline 17 & 4.14 & 3.35 & 0.79 & 4.24 & A \\
\hline 18 & 3.96 & 3.18 & 0.78 & 4.10 & A \\
\hline 19 & 3.77 & 3.04 & 0.73 & 4.16 & A \\
\hline 20 & 3.57 & 2.79 & 0.78 & 3.57 & A \\
\hline 21 & 3.45 & 2.78 & 0.67 & 4.14 & A \\
\hline 22 & 3.40 & 2.69 & 0.71 & 3.78 & $\mathbf{A}$ \\
\hline 23 & 3.37 & 2.68 & 0.69 & 3.88 & A \\
\hline 24 & 3.27 & 2.51 & 0.76 & 3.30 & A \\
\hline 25 & 3.10 & 2.41 & 0.69 & 3.49 & A \\
\hline 26 & 3.00 & 2.31 & 0.69 & 3.34 & A \\
\hline 27 & 2.90 & 2.34 & 0.56 & 4.17 & A \\
\hline 28 & 2.88 & 2.29 & 0.59 & 3.88 & A \\
\hline 29 & 2.82 & 2.26 & 0.56 & 4.03 & A \\
\hline 30 & 2.69 & 2.07 & 0.62 & 3.33 & A \\
\hline 31 & 2.53 & 1.97 & 0.56 & 3.51 & A \\
\hline 32 & 7.38 & 4.66 & 2.72 & 1.71 & $\mathbf{M}$ \\
\hline 33 & 6.27 & 3.39 & 2.88 & 1.17 & $\mathbf{M}$ \\
\hline 34 & 6.19 & 3.73 & 2.46 & 1.51 & $\mathbf{M}$ \\
\hline 35 & 5.04 & 3.64 & 1.40 & 2.6 & SM \\
\hline 36 & 2.68 & 1.48 & 1.20 & 1.2 & $\mathbf{M}$ \\
\hline$X$ & 10.04 & 5.83 & 4.21 & 1.38 & $\mathbf{M}$ \\
\hline $\mathrm{Y}$ & 4.69 & 2.74 & 1.95 & 1.4 & $\mathbf{M}$ \\
\hline
\end{tabular}

Table 1 presents the mean length of long and short arm ratio measurements of the 74 chromosomes of the dromedary which has been constructed on the basis of the position of the centromere and are also shown in Fig. 3. The fundamental number (FN) of chromosomes was calculated according to the hypothesis of Matthey (1945) that counts acrocentric as one 
and meta- and submetacentric chromosomes as two. Hence, the FN for the dromedary amounts to 86 and the fundamental number of autosomes (FNa) 82 .

\section{Discussion}

The diploid number of $C$. dromedarius was found to be 74 chromosomes, which has been previously been reported for the guanaco, the Bactrian camel and the vicugna in addition to the dromedary (Benirschke 1955, Taylor et al. 1968, Koulischer et al. 1971, Bunch et al. 1985). However, Capanna and Civitelli (1965) have reported 72 for the vicugna and guanaco, but the vicugna was found to have $2 n=74$ and more metacentric autosomes than the Bactrian camel (Koulischer et al. 1971). By means of the present technique it was possible to classify the chromosomes of the dromedary into 31 pairs of acrocentric autosomes, 4 pairs of metacentric autosomes, one pair of submetacentric autosomes and metacentric $\mathrm{X}$ and $\mathrm{Y}$ sex chromosomes. However, some authors have experienced some difficulties in classifying

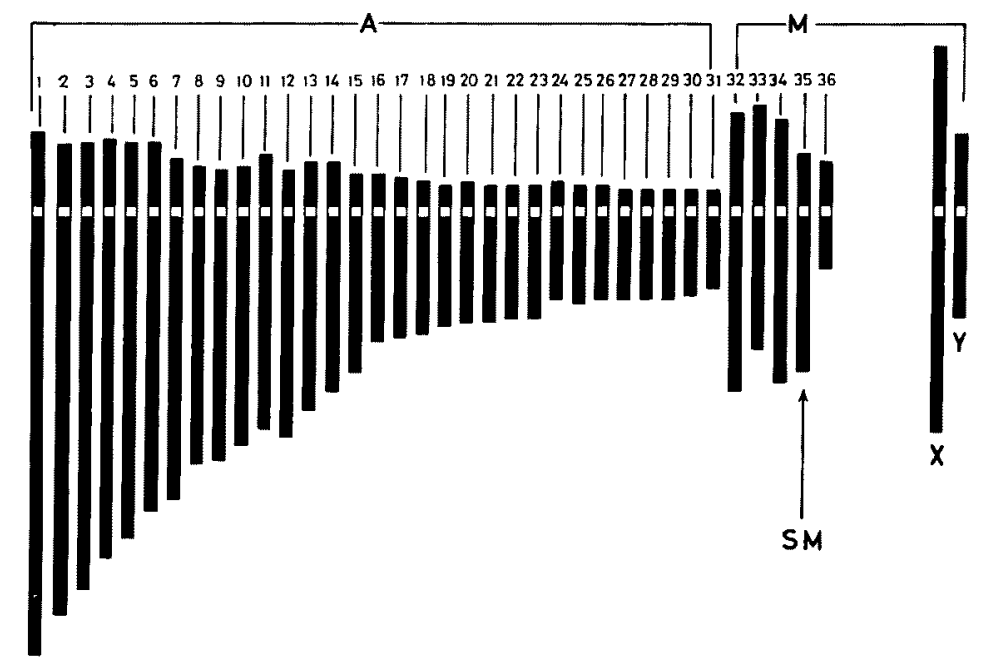

Fig. 3. An idiogram of Arabian camel, $C$. dromedarius chromosomes construced on the basis of the position of centromenes. A, acrocentric, M, metacentric and SM, submetacentric.

chromosomes of the Camelidae including Taylor et al. (1968) who found difficulties in classifying $\mathrm{Y}$ and smaller chromosomes of the dromedary and Koulischer et al. (1971) who were unable to classify chromosomes of the Bactrian camel and vicugna due to indiscernible morphology.

Bunch et al. (1985) have described G- and C-banding pattern homologies and chromosomes with NORs for the Bactrian camel, the Ilama and the guanaco that have a $2 \mathrm{n}$ of 74 and a karyotype of 33 pairs of acrocentric autosomes, 3 pairs of submetacentric autosomes, a large submetacentric $\mathrm{X}$ and a very small acrocentric $\mathrm{Y}$ chromosomes. There were no differences in either of the G- and C-band patterns in these animals, but the Bactrian camel has 5 pairs of nucleolus organizer chromosomes and both guanaco and Ilama six. These authors concluded that such identical patterns of chromosomes linear differentiation of the Camelidae might suggest that their karyotype must have been stable for many thousands of years.

Based on the C-banding technique carried out in the present study, the C-banded chromosomes of the Arabian camel proved to be different from those of other Camelidae. These include 5 pairs of metacentric and submetacentric autosomes, 31 pairs of acrocentric autosomes, a medium metacentric $\mathrm{X}$ and a small metacentric $\mathrm{Y}$ chromosomes. 


\section{Summary}

The chromosomes of the Arabian camel or the one humped camel, Camelus dromedarius, L. have been studied using cell cultures of peripheral blood lymphocytes. Using C-banding technique, the diploid chromosome number for the $C$. dromedarius was found to be 74 , with a karyotype consisting of 62 acrocentric, 8 metacentric and 2 submetacentric autosomes. The $\mathrm{X}$ chromosome is large, metacentric and the $\mathrm{Y}$ chromosome is a small metacentric sex chromosome. The fundamental number has been calculated to be 86 chromosomes.

\section{References}

Arrighi France, E. and Hsu, T. C. C. 1971. Localization of heterochromatin in human chromosomes. Cytogenetics 10: 81-86.

Benirschke, K. M., Malouf, N. and Heck, H. 1955. The chromosome complement of the Ilama. Chromo. Newsl. 15: 100-101.

Berland, H. M., Sharma, A., Cribiu, E. P., Darre, R. and Boscher, J. 1988. A new case of Robertsonian translocation in cattle. J. Hered. 79: 33-36.

Bostock, C. J. and Christie, S. 1974. Chromosome banding and DNA replication studies on a cell line of Dipodomys merriami. Chromosoma 48: 73-87.

Bruere, A. N., Zartama, D. L. and Chapman, H. M. 1974. The significance of the G-bands and C-bands of three different Robersonian translocations of domestic sheep (Ovis avies). Cytogenet. Cell Genet. 13: $479-488$.

Buckland, R. A. and Evans, H. J. 1978. Cytogenetic aspects of phylogeny in the Bovidae II. C-banding. Cytogenet. Cell Genet. 21: 64-71.

Bunch, T. D., Foote, W.C. and Maciulis, A. 1985. Chromosome banding pattern homologies and NORs for the Bactrian camel, guanaco, and Ilama. J. Hered. 76: 115-118.

Capanna, E. and Civitelli, M. V. 1965. The chromosomes of the three species of neotropical Camelidae. Mammal. Chrom. Newsl. 17: 75-79.

Craig-Holmes, A.P. and Shaw, M. W. 1971. Polymorphism of human constitutive heterochromatin. Science 174: 702-704.

Dev, V. G., Miller, D. A., Tantravahi, R., Schneck, R. R., Roderick, T. H., Erlanger, B. F. and Miller, O. J. 1975. Chromosome marker in Mus musculus: differences in C-banding between the subspecies $M$. m. musculus and M. m. molossinus. Chromosoma 53: 335-344.

Di Berardino, D. and Iannuzzi, L. 1981. Chromosome banding homologies in Swamp and Murrah buffalo. J. Hered. 72: 183-188.

Evans, H. J., Buckland, R. A. and Sumner, A. T. 1973. Chromosome homology and heterochromatin in goat, sheep and ox studied by banding techniques. Chromosoma 42: 383-402.

Goldoni, D., Rubini, M. and Fontana, F. 1984. Cytogenetic studies on Cervus elapus L. Constitutive heterochromatin and nucleolus organizer regions. Caryologia 37: 439-443.

Jorge, W. and Benirschke, K. 1977. Centromeric heterochromatin and G-banding of the red brocket deer, Mazama Americana temama (Cervoidea, Artiodactyla) with a probable non-Robertsonian translocation. Cytologia 42: 711-721.

Koulischer, L., Tijskens, J. and Montelmans, J. 1971. Mammalian cytogenetics IV. The chromosomes of two male Camelidae: Camelus bacterianus and Lama vicugna. Acta Zoologica ET Pathologica Antverpiensia 52: 89-92.

Levan, A., Fredga, K. and Sandberg. A. A. 1964. Nomenclature for centromeric position on chromsomes. Hereditas 52: 201-220.

Matthey, R. 1945. Levolution de la formule chromosomiale chezless vertebres. Experientia 1: 50-78.

Mayr, B., Krutzler, J., Kalat, M. and Schleger, W. 1987. NORs, heterochromatin, and R-bands in three species of Cervidae. J. Hered. 78: 108-110.

Pardue, M. L. and Gall, J. G. 1970. Chromosomal locatization of mouse satellite DNA. Science 168: 13561358.

Prescott, D. M., Bostock, C. J., Hatch, F. T. and Mazrimas, J. A. 1973. Location of satellite DNAs in the chromosomes of the kangaroo rat (Dipodomys ordii). Chromosoma 42: 205-213.

Schnedl, W. and Czaker, R. 1974. Centromeric heterochromatin and comparison of G-banding in cattle, goat, and sheep chromosomes (Bovidae). Cytgenet. Cell Genet. 13: 246-255. 
Sumner, A. T. 1972. A simple technique for demonstrating cenrtmeric heterochromatin. Exp. Cell Res. 75: 304-306.

Taylor, K. M., Hungerford, D. A., Snyder, R. L. and Ulmer, F. A. 1968 . Uniformity of karyotypes in the Camelidae. Cytogenetics 7: 8-15.

Van Tuinen, P., Robinson, T. J. and Feldhammer, G. A. 1983. Chromosome banding and NOR location in sika deer. J. Hered. 74: 473-474. 